\section{(O) OPEN ACCESS}

\title{
Once-daily budesonide MMX in active, mild-to-moderate ulcerative colitis: results from the randomised CORE II study
}

\author{
Simon P L Travis, ${ }^{1}$ Silvio Danese, ${ }^{2}$ Limas Kupcinskas, ${ }^{3}$ Olga Alexeeva, ${ }^{4}$ \\ Geert D'Haens, ${ }^{5}$ Peter R Gibson, ${ }^{6}$ Luigi Moro, ${ }^{7}$ Richard Jones, ${ }^{7}$ E David Ballard, ${ }^{8}$ \\ Johan Masure, ${ }^{9}$ Matteo Rossini, ${ }^{10}$ William J Sandborn ${ }^{11}$
}

For numbered affiliations see end of article.

\section{Correspondence to} Dr Simon P L Travis,

Translational Gastroenterology Unit, John Radcliffe Hospital, Oxford OX3 9DU, UK; simon.travis@ndm.ox.ac.uk

Received 4 December 2012 Revised 25 January 2013 Accepted 27 January 2013 Published Online First 22 February 2013

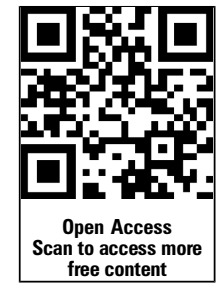

To cite: Travis SPL, Danese $S$, Kupcinskas L, et al. Gut 2014;63: 433-441.

\section{ABSTRACT}

Objective Budesonide MMX is a novel oral

formulation of budesonide that uses Multi-Matrix System (MMX) technology to extend release to the colon. This study compared the efficacy of budesonide MMX with placebo in patients with active, mild-to-moderate ulcerative colitis (UC).

Design Patients were randomised 1:1:1:1 to receive budesonide MMX $9 \mathrm{mg}$ or $6 \mathrm{mg}$, or Entocort EC $9 \mathrm{mg}$ (budesonide controlled ileal-release capsules; reference arm) or placebo once daily for 8 weeks. The primary endpoint was combined clinical and endoscopic remission, defined as UC Disease Activity Index score $\leq 1$ with a score of 0 for rectal bleeding and stool frequency, no mucosal friability on colonoscopy, and $a \geq 1$-point reduction in endoscopic index score from baseline. Results 410 patients were evaluated for efficacy. Combined clinical and endoscopic remission rates with budesonide MMX $9 \mathrm{mg}$ or $6 \mathrm{mg}$, Entocort EC and placebo were $17.4 \%, 8.3 \%, 12.6 \%$ and $4.5 \%$, respectively. The difference between budesonide MMX $9 \mathrm{mg}$ and placebo was significant (OR 4.49;95\% Cl 1.47 to $13.72 ; p=0.0047)$. Budesonide MMX 9 mg was associated with numerically higher rates of clinical (42.2\% vs $33.7 \%)$ and endoscopic improvement $(42.2 \%$ vs $31.5 \%$ ) versus placebo. The rate of histological healing $(16.5 \%$ vs $6.7 \% ; p=0.0361)$ and proportion of patients with symptom resolution $(23.9 \%$ vs $11.2 \%$; $p=0.0220$ ) were significantly higher for budesonide MMX 9 mg than placebo. Adverse event profiles were similar across groups.

Conclusion Budesonide MMX $9 \mathrm{mg}$ was safe and more effective than placebo at inducing combined clinical and endoscopic remission in patients with active, mild-to-moderate UC.

\section{INTRODUCTION}

Ulcerative colitis (UC) is a chronic inflammatory disease of the colon and rectum characterised by intermittent flares of active disease with diarrhoea, rectal bleeding and rectal urgency, alternating with periods of remission. ${ }^{1-3}$ Corticosteroids, such as prednisolone, are effective for inducing rapid remission in active $\mathrm{UC}$, but due to their adverse effects they are usually reserved for patients who have failed mesalazine (5-aminosalicylic acid; 5-ASA), patients who need a prompt response or those with severe disease. ${ }^{3}$ The European Crohn's

\section{Significance of this study}

What is already known on this subject?

- Ulcerative colitis (UC) is a chronic, debilitating inflammatory disease of the colon and rectum.

- Corticosteroids are effective in treating active UC, but due to their adverse effects, are usually reserved for selected patients.

- Budesonide, coupled with a colonic release system (MMX Multi-Matrix System) has demonstrated promising clinical efficacy in UC, while minimising systemic side effects.

What are the new findings?

- Here, we have investigated the efficacy of once-daily budesonide MMX for the induction of combined clinical and endoscopic remission in patients with active, mild-to-moderate UC compared with placebo and an active control.

- Budesonide MMX 9 mg provided a statistically significant increase in the combined clinical and endoscopic remission rate compared with placebo ( $17.4 \%$ vs $4.5 \%$; $p=0.0047)$.

- Furthermore, budesonide MMX $9 \mathrm{mg}$ improved the rates of histological healing and symptom resolution compared with placebo.

How might it impact on clinical practice in the foreseeable future?

- Colonic-release budesonide may be a useful alternative to conventional corticosteroid therapy for the treatment of active, mild-to-moderate UC.

- In addition, our data highlight the value of using robust endpoints and ensuring histological evidence of active disease prior to initiating studies of anti-inflammatory agents in UC.

and Colitis Organisation guidelines recommend that active, mild-to-moderate UC should initially be treated with oral mesalazine $>2 \mathrm{~g} /$ day, with systemic corticosteroids reserved for patients with symptoms of active colitis whose disease does not respond to mesalazine. ${ }^{3}$

Oral budesonide is a topically acting corticosteroid with low bioavailability and few systemic side 
effects. Budesonide's safety and efficacy profiles are well characterised in the treatment of several inflammatory conditions, from asthma and allergies to inflammatory bowel disease. ${ }^{5-7}$ The local activity of budesonide in the colonic mucosa is the key to efficacy. Current oral formulations of budesonide, such as Budenofalk and Entocort EC, release the drug only in the distal ileum and proximal colon ${ }^{8}$ and so are not optimally designed for the anatomical distribution of UC. The $\mathrm{pH}$-dependent release of these formulations means that there is no effective rate-controlling mechanism to ensure extended release of the drug along the entire length of the colon. In a recent study, oral $\mathrm{pH}$-modified release budesonide was significantly less effective than mesalazine for inducing clinical remission in active UC (risk ratio $0.72 ; 95 \%$ CI 0.57 to 0.91 ), which may be due to unreliable colonic release in patients with altered intestinal $\mathrm{pH}^{9}$

To improve the release of budesonide, it can be coupled with a colonic release system (MMX Multi-Matrix System) that provides targeted drug delivery to the entire colon, as supported by scintigraphic data. ${ }^{10}$ This technology has already been used successfully with oral mesalazine (mesalazine MMX). ${ }^{21-13}$ The goal of budesonide MMX treatment is to maintain the efficacy of corticosteroids while minimising systemic side effects. Preliminary data in patients with left-sided UC showed that $47.1 \%$ of patients treated with budesonide MMX $9 \mathrm{mg}$ once daily achieved clinical improvement (clinical remission, defined as a Rachmilewitz Clinical Activity Index (CAI) score of $\leq 4$, or a $\geq 50 \%$ reduction in CAI score from baseline) at 4 weeks, compared with $33.3 \%$ of those treated with placebo, suggesting that this formulation might be a viable new treatment option. ${ }^{14}$

The objective of this phase III CORE (Colonic Release budesonide) study was to investigate the efficacy of once-daily budesonide MMX for the induction of combined clinical and endoscopic remission in patients with active, mild-to-moderate UC compared with placebo. A non-powered, internal reference arm of oral budesonide controlled ileal-release capsules (Entocort EC) was included as an active control to conform with regulatory requirements. Because the clinical trial was conducted in 15 countries in the European Union (EU) and outside the EU, ileal-release budesonide was chosen due to its presence in each market which was essential to gain approval to conduct the study from local agencies.

\section{PATIENTS AND METHODS}

\section{Patients}

Men and women aged 18-75 years with UC for $\geq 6$ months, diagnosed according to international criteria, ${ }^{3}$ were eligible to participate if they had active, mild-to-moderate disease, defined as a UC Disease Activity Index (UCDAI) score of $\geq 4$ and $\leq 10 .{ }^{15}{ }^{16}$ Although not an inclusion criterion, to be included in the efficacy analyses, patients also had to have histological evidence of active UC identified via mucosal biopsy at baseline. Investigators were instructed to obtain three biopsies from the most severely affected areas following examination of each segment of the colonic mucosa. Histological confirmation was obtained via a central histopathologist in an independent lab with examinations performed in batches to maintain homogeneity and blinded conditions while preserving the trial from any possible bias. Concomitant UC medications were not allowed; for patients receiving oral 5-ASA at the screening visit, oral 5 -ASA medication was required to be washed out $\geq 2$ days and rectal ASAs had a 4 -week washout prior to randomisation.

Patients were excluded from the study if they had infection (defined as the presence of any enteric pathogens (eg, Shigella spp, Clostridium spp, Salmonella spp, ova and parasites) or
Clostridium difficile toxins A or B) or limited proctitis (UC limited to the rectum $\leq 15 \mathrm{~cm}$ above the dentate line); or if they had used oral or rectal steroids in the last 4 weeks, immunosuppressive agents in the last 8 weeks or anti-tumour necrosis factor agents in the last 3 months. Further exclusion criteria included severe colitis (UCDAI score $>10$ ); evidence or history of toxic megacolon; severe anaemia (haemoglobin $<10.5 \mathrm{~g} / \mathrm{dl}$ ), leucopoenia or granulocytopenia; pregnancy or lactation; use of cytochrome P450 3A4 inducers or inhibitors (eg, ketoconazole, phenytoin) or antibiotics; severe disease of other organs/systems; liver cirrhosis, or evident hepatic or renal disease/insufficiency; type I diabetes; glaucoma; hepatitis $\mathrm{B} / \mathrm{C}$; and HIV infection.

The protocol was approved by all relevant ethics committees and the study was conducted in accordance with the principles of Good Clinical Practice (GCP), the Declaration of Helsinki, and all applicable regulations related to clinical trials in the participating countries. Patients provided written consent prior to any study-related procedure (ClinicalTrials.gov: NCT00679380).

\section{Study design}

This was a phase III, randomised, double-blind, double-dummy, placebo-controlled, parallel-group trial carried out at 69 centres in 15 countries in Europe, Russia, Israel and Australia. Patients were randomised 1:1:1:1 to receive budesonide MMX $9 \mathrm{mg} / \mathrm{day}$, budesonide MMX $6 \mathrm{mg} / \mathrm{day}$, Entocort EC $9 \mathrm{mg} / \mathrm{day}(3 \times 3 \mathrm{mg}$ capsules) taken once daily in the morning; active reference arm), or placebo, administered once daily for 8 weeks. Randomisation was conducted centrally via an interactive voice response system (IVRS). Study medication was taken after breakfast every day; each patient took one tablet and three capsules per day of active or placebo study medication according to the randomisation schedule. To maintain blinding, a double-dummy technique, with placebo tablets of budesonide MMX and placebo overencapsulated Entocort EC, was used. Scheduled full assessment visits were undertaken at screening and at week 8 (day $56, \pm 2$ days) with intermediate control assessment of clinical conditions at randomisation (day 1), and at weeks 2 and 4. Assessments included full colonoscopy (not flexible sigmoidoscopy), baseline stool tests to exclude infectious colitis, blood and urine samples, evaluation of patient diaries, mucosal biopsy samples and pill count.

\section{Endpoints}

The primary endpoint was combined clinical and endoscopic remission at week 8 , strictly defined as a total UCDAI score $\leq 1$, with a rectal bleeding score of 0 , stool frequency score of 0 , mucosal appearance score of 0 (no sign of mucosal friability on full colonoscopy) and a $\geq 1$-point reduction in baseline endoscopic index (EI) score ${ }^{17}$ at week 8 . Secondary endpoints were clinical improvement, defined as a $\geq 3$-point improvement in the UCDAI score from baseline to week 8 , and endoscopic improvement, defined as a $\geq 1$-point reduction in the endoscopy subscore of the UCDAI from baseline to week 8. Other endpoints included histological healing, defined as a total score of $\leq 1$ (Saverymuttu criteria ${ }^{18}$ ) for histological assessment of all biopsy specimens, and symptom resolution, defined as rectal bleeding and stool frequency UCDAI subscores of 0 at week 8 . Clinical and endoscopic remission rates were also examined in an exploratory subgroup analysis, for which data were stratified by median age, gender and geographical region.

\section{Safety assessments}

Safety assessments included adverse event (AE) reporting, potential glucocorticoid-related effects and morning plasma 
cortisol (assessed at baseline (mean of two samples taken on different days prior to randomisation) and week 8/final visit). All AEs were coded according to the Medical Dictionary for Regulatory Activities V.11.0.

\section{Sample size determination and statistical analysis}

Assuming a difference of 20 percentage points between at least one budesonide MMX treatment group (estimated remission rate of $47 \%$ ) and placebo (estimated remission rate of $27 \%$ ) at week 8,110 patients per group provided $80 \%$ power to detect a statistically significant difference between at least one budesonide MMX treatment group and placebo at the two-sided $\alpha=0.025$ level of significance. Assuming a dropout rate of approximately $10 \%, 123$ patients per group or 492 patients total were to be randomised in this study. The study was not powered to detect a statistically significant difference between the budesonide MMX and Entocort groups.

The primary efficacy analysis for superiority of budesonide MMX $9 \mathrm{mg}$ or $6 \mathrm{mg}$ versus placebo was based on a $\chi^{2}$ test at a two-sided significance level of $\alpha=0.025$. A hierarchical testing procedure was used for the analyses of primary and secondary endpoints at the $\alpha=0.025$ level of significance. If at least one primary endpoint comparison was statistically significant, then both dosage strengths were compared with placebo with respect to the first secondary endpoint (clinical improvement). If at least one secondary endpoint comparison for clinical improvement was statistically significant according to the $\chi^{2}$ test, then both dosage strengths were compared with placebo with respect to the second secondary endpoint (endoscopic improvement). For other endpoints (histological healing and symptom resolution) and all analyses of Entocort versus placebo (all endpoints), an exploratory two-sided significance level of $\alpha=0.05$ was applied. In the subgroup analyses, the effect of demographic variables on the primary endpoint were investigated using the Cochran Mantel-Haenszel test at a two-sided significance level of $\alpha=0.05$. Differences between active treatments and placebo with regard to the mean change from baseline in morning plasma cortisol levels at week 8 were analysed using the
Wilcoxon rank-sum test at a two-sided significance level of $\alpha=0.05$.

Efficacy endpoints were prespecified in the statistical analysis plan to be analysed in the modified intention to treat (mITT) population (all randomised patients who received at least one dose of study medication, with active histological disease at baseline and no major violations of GCP or entry criteria (ie, infectious colitis)), consistent with the 2008 European Medicines Agency guidelines on clinical trials of active UC. Active disease was determined via a central histopathologist and is described above. Patients in the mITT population were analysed according to the treatment they were randomised to receive. The safety population consisted of patients who had received at least one dose of study medication and were analysed according to which treatment they received. Missing data were handled using the worst-case method.

ORs and associated 95\% CIs were also calculated using standard logistic regression methodology. ${ }^{19} 20$

\section{RESULTS}

\section{Patients}

The study was conducted between July 2008 and February 2010. A total of 613 patients were screened and 512 were randomised. Of the 512 randomised patients, three did not receive study medication. The safety population consisted of 511 patients who received at least one dose of study medication, including two patients who received treatment with budesonide MMX $9 \mathrm{mg}$, but who were not randomised through the IVRS. A total of 509 treated patients were randomised into the four treatment arms: placebo $(\mathrm{n}=129)$, budesonide MMX $9 \mathrm{mg}$ $(n=126)$, budesonide MMX $6 \mathrm{mg}(n=128)$ and Entocort EC $9 \mathrm{mg}(\mathrm{n}=126)$ (figure 1). From within the safety population, a total of 101 patients were excluded from the efficacy analyses as per figure 1. Among the exclusions, 77 patients had normal histopathology at baseline, 50 had documented GCP violations and one had infectious colitis at screening. Two patients were not randomised. Some patients had more than one reason for exclusion. Of the 410 patients in the mITT population, 89
Figure 1 Patient flow and disposition. $A E$, adverse event; Bud, budesonide; GCP, Good Clinical Practice; mITT, modified intention to treat; QD, daily.

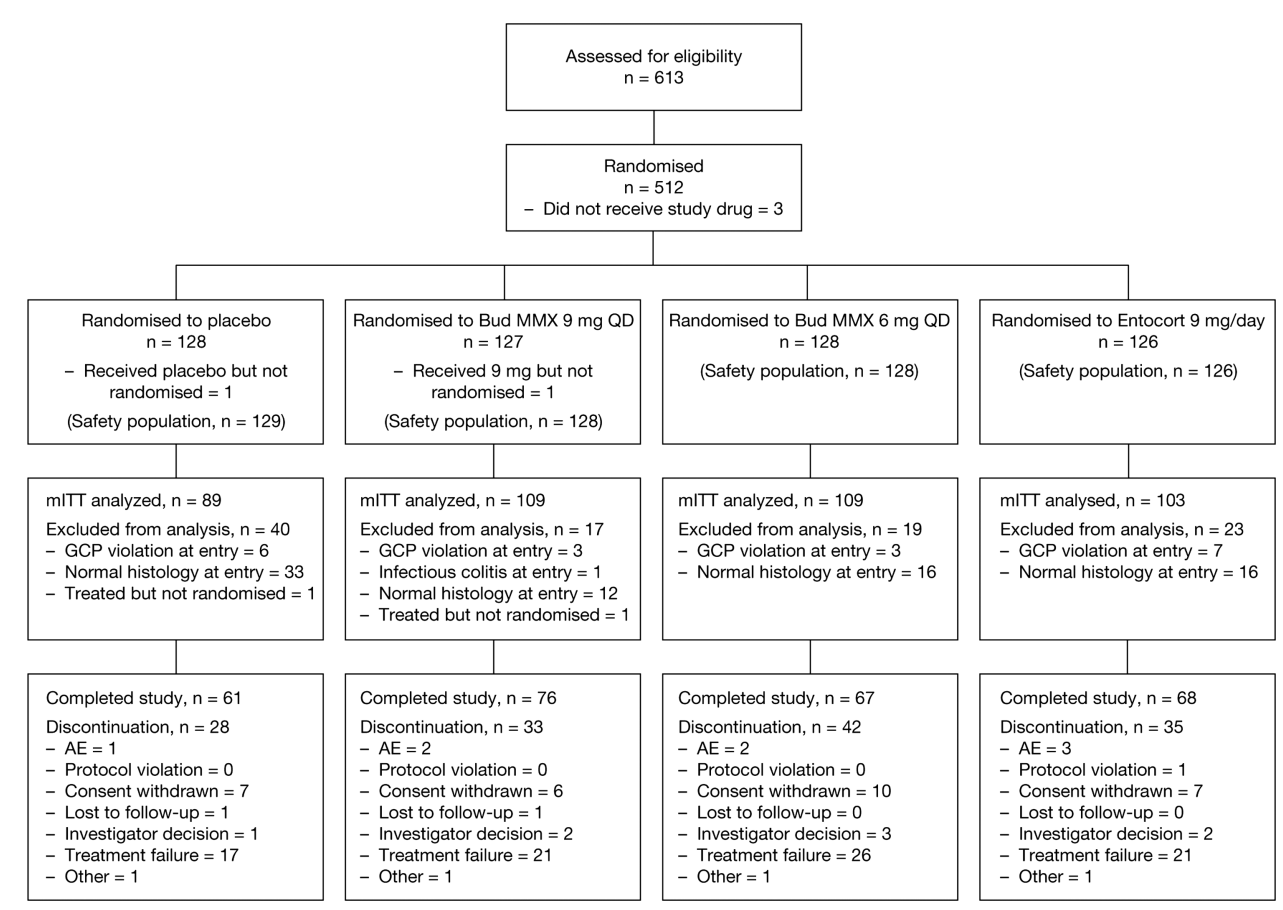


received placebo, 109 received budesonide MMX 9 mg, 109 received budesonide MMX $6 \mathrm{mg}$, and 103 received Entocort EC $9 \mathrm{mg}$. In the mITT population, 138 patients discontinued the study before week 8 . The reasons for premature withdrawals were similar across treatment groups. Baseline patient demographics and clinical characteristics are shown in table 1.

\section{Efficacy outcomes}

Primary endpoint

Combined clinical and endoscopic remission at week 8 was achieved in 17.4\% of patients in the budesonide MMX $9 \mathrm{mg}$ group, $8.3 \%$ of those in the budesonide MMX $6 \mathrm{mg}$ group, $12.6 \%$ of those in the Entocort EC group and $4.5 \%$ of patients in the placebo group (figure 2). The rate of combined clinical and endoscopic remission with budesonide MMX $9 \mathrm{mg}$ was significantly higher than with placebo $(17.4 \%$ vs $4.5 \%$; OR 4.49 ; 95\% CI 1.47 to $13.72 ; \mathrm{p}=0.0047$ ) (figures 2 and 3). Although numerically more patients achieved combined clinical and endoscopic remission with budesonide MMX 6 mg compared with placebo, this difference did not reach statistical significance.

Subgroup analyses were performed for the mutually exclusive categories of left-sided disease (disease limited to the left side of the colon up to the splenic flexure) and extensive disease (disease extending beyond the splenic flexure). In patients with left-sided disease, the clinical and endoscopic remission rate for budesonide MMX $9 \mathrm{mg}$ was significantly greater than placebo $(17.7 \%$ vs $5.8 \%, \mathrm{p}=0.0268)$. For extensive disease, clinical and endoscopic remission rates were numerically greater in the budesonide MMX $9 \mathrm{mg}$ compared with placebo $(13.8 \%$ vs $0.0 \%, \mathrm{p}=0.1350$ ). A sensitivity analysis of combined clinical and endoscopic remission in the conventional intention-to-treat population (ie, all randomised and dosed patients; $n=509$ ), in which all patients excluded from the mITT population were considered as not achieving remission, demonstrated similar

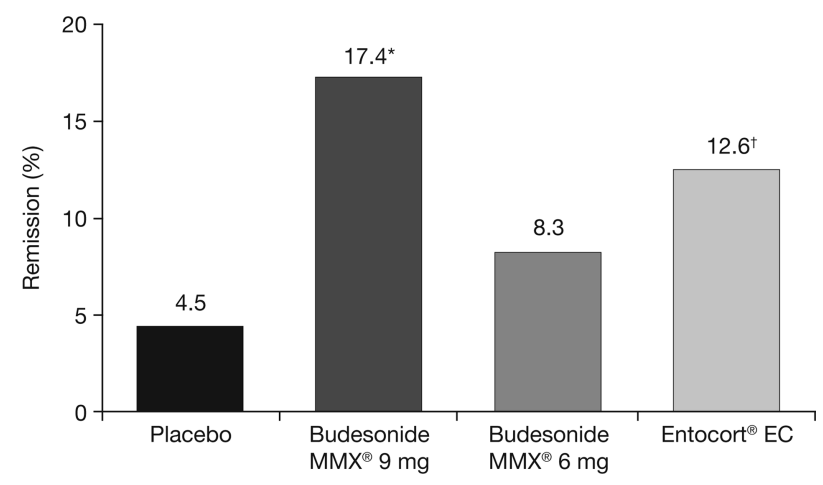

Figure 2 Primary endpoint: combined clinical and endoscopic remission at week 8 (modified intention-to-treat population; $n=410$ ). Statistically significant versus placebo at the ${ }^{*} \alpha=0.025(p=0.0047)$ or $+\alpha=0.05(p=0.0481)$ level. Not powered to show statistical difference between budesonide Multi-Matrix System (MMX) treatment arms and Entocort EC.

remission rates to the $\mathrm{mITT}$ analysis (budesonide MMX $9 \mathrm{mg}$ 15.1\%, budesonide MMX $6 \mathrm{mg}$ 7.0\%, Entocort EC 10.3\%, placebo 3.1\%; $\mathrm{p}=0.0008$ for budesonide MMX $9 \mathrm{mg}$ vs placebo). Prespecified stratified subgroup analyses of combined clinical and endoscopic remission rates confirmed statistical differences in remission rates between budesonide MMX $9 \mathrm{mg}$ and placebo for younger patients (aged $\leq 43.5$ years; $p=0.0195$ ), men $(\mathrm{p}=0.0246)$ and Eastern European patients $(\mathrm{p}=0.0227)$.

\section{Secondary endpoints}

Compared with placebo, numerically more patients treated with budesonide MMX $9 \mathrm{mg}$ achieved clinical improvement $(42.2 \%$ vs 33.7\%; OR 1.44; table 2 and figure 3), but statistical significance was not reached. Clinical improvement rate in the

Table 1 Baseline patient demographics and clinical characteristics (safety population; $n=511$ )

\begin{tabular}{|c|c|c|c|c|}
\hline Parameter & $\begin{array}{l}\text { Placebo } \\
(n=129)\end{array}$ & Budesonide MMX 9 mg, ( $n=128)$ & Budesonide MMX $6 \mathrm{mg},(\mathrm{n}=128)$ & Entocort EC $(n=126)$ \\
\hline Mean age, years (range) & $39.9(12-68)$ & $37.6(13-66)$ & $37.9(14-66)$ & $36.7(12-67)$ \\
\hline \multicolumn{5}{|l|}{ Gender, $\mathrm{n}(\%)$} \\
\hline Men & 77 (59.7) & $70(54.7)$ & $67(52.3)$ & $66(52.4)$ \\
\hline Women & $52(40.3)$ & $58(45.3)$ & $61(47.7)$ & $60(47.6)$ \\
\hline \multicolumn{5}{|l|}{ Race, n (\%) } \\
\hline White & $129(100.0)$ & $126(98.2)$ & $128(100.0)$ & $126(100.0)$ \\
\hline Asian & 0 & $1(0.9)$ & 0 & 0 \\
\hline Other & 0 & $1(0.9)$ & 0 & 0 \\
\hline \multicolumn{5}{|l|}{ UC history } \\
\hline Mean disease duration, years & 6.3 & 5.5 & 5.7 & 6.3 \\
\hline Duration $\leq 1$ year, $\mathrm{n}(\%)$ & $23(17.8)$ & $28(21.9)$ & $19(14.8)$ & $22(17.5)$ \\
\hline Duration $>1$ to $\leq 5$ years, $\mathrm{n}(\%)$ & $55(42.6)$ & $55(43.0)$ & $62(48.4)$ & $45(35.7)$ \\
\hline Duration $>5$ years, $n(\%)$ & $51(39.5)$ & $44(34.4)$ & $47(36.7)$ & $59(46.8)$ \\
\hline \multicolumn{5}{|l|}{ Disease extent, $\mathrm{n}(\%)$} \\
\hline Proctosigmoiditis & $64(49.6)$ & $58(45.3)$ & $58(45.3)$ & $51(40.5)$ \\
\hline Left-sided colitis & $44(34.1)$ & $37(28.9)$ & $40(31.3)$ & $49(38.9)$ \\
\hline Extensive/pancolitis & $20(15.5)$ & $31(24.2)$ & $29(22.7)$ & $26(20.6)$ \\
\hline Mean baseline UCDAI score & 6.2 & 6.5 & 6.6 & 6.7 \\
\hline Mean baseline El score & 6.6 & 6.5 & 7.2 & 6.5 \\
\hline Prior mesalazine use* & $75(58.1)$ & $66(51.6)$ & $77(60.2)$ & $70(55.6)$ \\
\hline Prior sulfasalazine use* & $28(21.7)$ & $33(25.8)$ & $27(21.1)$ & $30(23.8)$ \\
\hline
\end{tabular}

*Prior medications are medications which started prior to the first dose of study drug.

El, Endoscopic Index; MMX, Multi-Matrix System, UC, ulcerative colitis; UCDAI, UC Disease Activity Index. 


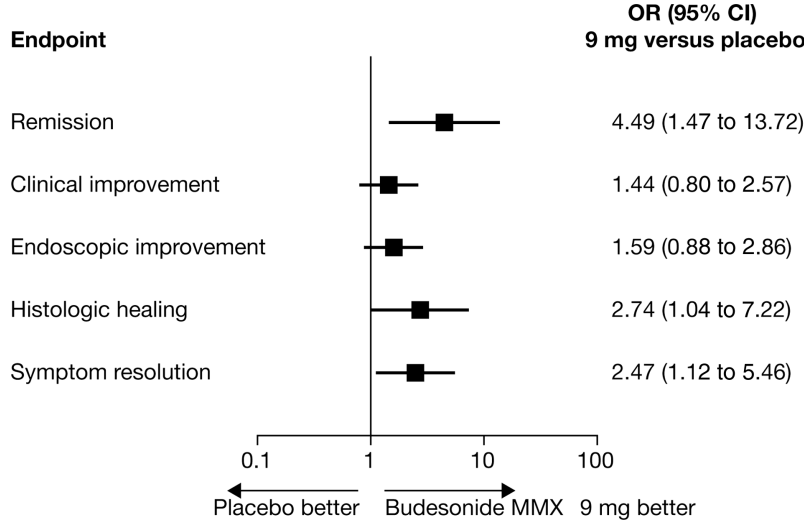

Figure 3 OR analysis of budesonide Multi-Matrix System $9 \mathrm{mg}$ versus placebo.

budesonide MMX $6 \mathrm{mg}$ group was also not statistically different to that in the placebo group $(25.7 \%$ vs $33.7 \%$; table 2$)$. Endoscopic improvement rate was numerically higher with budesonide MMX $9 \mathrm{mg}$ than with placebo $(42.2 \%$ vs $31.5 \%$; OR 1.59; table 2 and figure 3). As per the prespecified hierarchical statistical analysis plan, statistical comparison of endoscopic improvement rate between budesonide MMX $9 \mathrm{mg}$ and placebo was not performed. Endoscopic improvement rate for budesonide MMX 6 mg was $25.7 \%$ vs $31.5 \%$ for placebo. Table 2 also shows that clinical improvement and endoscopic improvement rates were numerically higher in patients treated with budesonide MMX $9 \mathrm{mg}$ than in the Entocort EC control arm. However, the study was not powered to detect statistical significance between the budesonide MMX and Entocort EC treatment groups.

\section{Other endpoints}

Significantly more patients achieved histological healing $(16.5 \%$ vs $6.7 \%, \mathrm{p}=0.0361$; OR 2.74; 95\% CI 1.04 to 7.22 ) and complete symptom resolution $(23.9 \%$ vs $11.2 \%, \mathrm{p}=0.0220$; OR $2.47 ; 95 \%$ CI 1.12 to $5.46 ; 36.1 \%$ vs $17.5 \%, p=0.0196$ in observed cases only (data not shown)) with budesonide MMX $9 \mathrm{mg}$ compared with placebo (table 2 and figure 3). Numerically more patients achieved histological healing $(9.2 \%$ vs $6.7 \%)$ and symptom resolution (13.8\% vs 11.2\%) with budesonide MMX 6 mg compared with placebo, but differences were not statistically significant (table 2).

\section{Safety}

The numbers of patients with treatment-emergent AEs (TEAEs), treatment-related TEAEs, TEAEs leading to discontinuation and serious TEAEs were similar across all four treatment groups (table 3). The nature and severity of TEAEs were also comparable across groups, with the majority of patients with TEAEs experiencing events that were mild or moderate in severity (table 3). The most common TEAEs in the placebo, budesonide MMX $9 \mathrm{mg}$ and $6 \mathrm{mg}$, and Entocort EC groups were UC relapse $(11.6 \%, 15.6 \%, 21.1 \%$ and $12.7 \%$ respectively) and headache $(6.2 \%, 16.4 \%, 15.6 \%$ and $7.1 \%$, respectively) (table 3). Serious TEAEs led to discontinuation in nine patients and four patients experienced treatment-related serious TEAEs (treatment failure with budesonide MMX $9 \mathrm{mg}$, UC relapse/ nausea/urge incontinence with budesonide MMX $6 \mathrm{mg}$ and gastric ulcer/UC relapse with Entocort EC). Worsening of potential glucocorticoid-related effects occurred infrequently during the study (table 4). The most frequent worsened potential glucocorticoid-related signs or symptoms were mood changes $(3.5 \%)$, sleep changes $(3.3 \%)$ and insomnia (1.6\%). No notable differences were observed between the active treatment and placebo groups with regard to these effects.

At week 8, mean morning plasma cortisol concentrations of 253 and $315 \mathrm{nmol} /$ litre (reference range: 138-690 nmol/litre) were measured in the budesonide MMX $9 \mathrm{mg}$ and $6 \mathrm{mg}$ groups, respectively, representing a decrease from baseline of 103 and $48 \mathrm{nmol} /$ litre, respectively. A mean decrease from baseline of $47 \mathrm{nmol} /$ litre was also observed in the Entocort EC group, resulting in a week 8 mean morning plasma cortisol concentration of $323 \mathrm{nmol} /$ litre. In contrast, the mean morning plasma cortisol concentration in the placebo group increased by $28 \mathrm{nmol} /$ litre from a baseline value of $337 \mathrm{nmol} /$ litre. Differences in mean change in morning plasma cortisol levels from baseline to week 8 were statistically significant between treatment groups (MMX $9 \mathrm{mg}$ or $6 \mathrm{mg}$ vs placebo, $\mathrm{p}<0.0001$; Entocort EC vs placebo; $\mathrm{p}=0.0004)$; however, absolute mean concentrations remained within the normal reference range for all treatment groups at all time points.

\section{DISCUSSION}

This study demonstrates the efficacy and safety of budesonide MMX $9 \mathrm{mg}$ for inducing combined clinical and endoscopic remission in patients with active, mild-to-moderate UC. Budesonide MMX $9 \mathrm{mg}$ provided a statistically significant increase in the stringently defined combined clinical and endoscopic remission rate compared with placebo $(17.4 \%$ vs $4.5 \%$; $\mathrm{p}=0.0047$ ). Furthermore, budesonide MMX $9 \mathrm{mg}$ improved the rates of histological healing and symptom resolution compared with placebo. The notable features of this trial are its stringent definition of remission, the decision to analyse efficacy only in patients with objective, histological evidence of active inflammation at baseline, and the use of full colonoscopy (rather than flexible sigmoidoscopy) for endoscopic assessment.

Table 2 Secondary and other endpoints: clinical improvement, endoscopic improvement, histological healing and symptom resolution from baseline to week 8 (mlTT population; $\mathrm{n}=410$ )

\begin{tabular}{lllll}
\hline Efficacy parameter & $\begin{array}{l}\text { Placebo }(\mathbf{n}=89) \\
\mathbf{n}(\%)\end{array}$ & $\begin{array}{l}\text { Budesonide MMX 9 mg, }(\mathbf{n}=109) \\
\mathbf{n}(\%)\end{array}$ & $\begin{array}{l}\text { Budesonide MMX 6 mg, }(\mathbf{n}=109) \\
\mathbf{n}(\%)\end{array}$ & $\begin{array}{l}\text { Entocort EC }(\mathbf{n}=103) \\
\mathbf{n}(\%)\end{array}$ \\
\hline Clinical improvement & $30(33.7)$ & $46(42.2)$ & $28(25.7)$ & $34(33.0)$ \\
Endoscopic improvement & $28(31.5)$ & $46(42.2)$ & $28(25.7)$ & $38(36.9)$ \\
Histological healing & $6(6.7)$ & $18(16.5)^{*}$ & $10(9.2)$ & $14(13.6)$ \\
Symptom resolution & $10(11.2)$ & $26(23.9)^{*}$ & $15(13.8)$ & $19(18.4)$ \\
\hline
\end{tabular}


Table 3 Summary of TEAEs (safety population, $n=511$ )

\begin{tabular}{|c|c|c|c|c|c|}
\hline & $\begin{array}{l}\text { Placebo } \\
(n=129) \\
n(\%)\end{array}$ & $\begin{array}{l}\text { Budesonide MMX } 9 \mathrm{mg} \text {, } \\
(\mathrm{n}=128) \\
\mathrm{n}(\%)\end{array}$ & $\begin{array}{l}\text { Budesonide MMX } 6 \text { mg, } \\
(n=128) \\
n(\%)\end{array}$ & $\begin{array}{l}\text { Entocort EC } \\
(n=126) \\
n(\%)\end{array}$ & $\begin{array}{l}\text { Total } \\
(n=511) \\
n(\%)\end{array}$ \\
\hline Any TEAE & $57(44.2)$ & $71(55.5)$ & $80(62.5)$ & $69(54.8)$ & $277(54.2)$ \\
\hline Related TEAEs* & $31(24.0)$ & $33(25.8)$ & $28(21.9)$ & $29(23.0)$ & $121(23.7)$ \\
\hline \multicolumn{6}{|l|}{ Severity of TEAEs } \\
\hline Severe & $5(3.9)$ & $12(9.4)$ & $5(3.9)$ & $10(7.9)$ & $32(6.3)$ \\
\hline TEAEs leading to discontinuation & $19(14.7)$ & $24(18.8)$ & $30(23.4)$ & $22(17.5)$ & $95(18.6)$ \\
\hline Any serious TEAEs & $5(3.9)$ & $4(3.1)$ & $3(2.3)$ & $1(0.8)$ & $13(2.5)$ \\
\hline Related serious TEAEs* & 0 & $1(0.8)$ & $2(1.6)$ & $1(0.8)$ & $4(0.8)$ \\
\hline $\begin{array}{l}\text { Serious TEAEs leading to } \\
\text { discontinuation }\end{array}$ & $2(1.6)$ & $4(3.1)$ & $2(1.6)$ & $1(0.8)$ & $9(1.8)$ \\
\hline Flatulence & $3(2.3)$ & $5(3.9)$ & $7(5.5)$ & $7(5.6)$ & $22(4.3)$ \\
\hline Nausea & $3(2.3)$ & $8(6.3)$ & $7(5.5)$ & $3(2.4)$ & $21(4.1)$ \\
\hline Nasopharyngitis & $2(1.6)$ & $1(0.8)$ & $8(6.3)$ & $6(4.8)$ & $17(3.3)$ \\
\hline Blood cortisol decrease & $1(0.8)$ & $7(5.5)$ & $3(2.3)$ & $4(3.2)$ & $15(2.9)$ \\
\hline
\end{tabular}

The absolute clinical and endoscopic remission rates seen in this study are lower than the remission rates reported in several recent UC trials. ${ }^{2} 911$ There are a number of potential reasons for these differences, which relate primarily to the study endpoints and inclusion/evaluation criteria used. A key factor is the criteria used to define remission. ${ }^{21}$ The current study set a high goal: a total UCDAI score of $\leq 1$ with normal stool frequency and no rectal bleeding, together with a $\geq 1$-point reduction in baseline EI score and no mucosal friability on complete colonoscopy. This definition was chosen partly to minimise the placebo response, but also to have an outcome that was clinically relevant. Patients can detect a noticeable benefit from treatment when their symptoms, such as rectal bleeding and increased stool frequency, are alleviated. Additionally, endoscopic improvements, particularly mucosal healing, may be an important indicator of longer-term outcomes, such as the likelihood of colectomy over the following year. ${ }^{22}$ In their study comparing
Budenofalk with Salofalk, Gross et $a l^{9}$ defined remission as a Rachmilewitz CAI score of $\leq 4$, which might mean anything up to a score of 2 for stool frequency (defined as 30-60 bowel actions/week) and 2 for rectal bleeding (defined as a little blood). The mesalazine MMX studies $^{2} 11 \quad 12$ used similar UCDAI criteria to our study, but employed a less thorough method (flexible sigmoidoscopy) for endoscopic evaluation. The entry criteria were also different from those used in the current study, particularly those relating to disease characteristics (newly diagnosed patients and patients with established disease were recruited, but only those with a current flare duration $\leq 6$ weeks), relapse history (patients relapsing on maintenance mesalazine $>2.0 \mathrm{~g} /$ day and those relapsing within 2 weeks of a dose reduction from $>2.0$ to $\leq 2.0 \mathrm{~g} /$ day were not eligible), and prior treatment response (patients with unsuccessful treatment of their current flare with steroids or mesalazine $>2.0 \mathrm{~g} / \mathrm{day}$ were not eligible). These factors, combined with the less

Table 4 Worsened potential glucocorticoid-related signs or symptoms occurring during treatment (safety population; $\mathrm{n}=511$ )

\begin{tabular}{|c|c|c|c|c|c|}
\hline $\begin{array}{l}\text { Worsened glucocorticoid signs/ } \\
\text { symptoms* }\end{array}$ & $\begin{array}{l}\text { Placebo } \\
(\mathrm{n}=129) \\
\mathrm{n}(\%)\end{array}$ & $\begin{array}{l}\text { Budesonide MMX } 9 \mathrm{mg} \text {, } \\
(\mathrm{n}=128) \\
\mathrm{n}(\%)\end{array}$ & $\begin{array}{l}\text { Budesonide MMX } 6 \text { mg, } \\
(\mathrm{n}=128) \\
\mathrm{n}(\%)\end{array}$ & $\begin{array}{l}\text { Entocort EC } \\
(n=126) \\
n(\%)\end{array}$ & $\begin{array}{l}\text { Total } \\
(\mathrm{n}=511) \\
\mathrm{n}(\%)\end{array}$ \\
\hline Any effect & $13(10.1)$ & $8(6.3)$ & $6(4.7)$ & $14(11.1)$ & $41(8.0)$ \\
\hline Moon face & $4(3.1)$ & $2(1.6)$ & 0 & $1(0.8)$ & $7(1.4)$ \\
\hline Flushing & $1(0.8)$ & 0 & $1(0.8)$ & $1(0.8)$ & $3(0.6)$ \\
\hline Fluid retention & $2(1.6)$ & 0 & 0 & 0 & $2(0.4)$ \\
\hline Mood changes & 7 (5.4) & $2(1.6)$ & $3(2.4)$ & $6(4.8)$ & $18(3.5)$ \\
\hline Sleep changes & $4(3.1)$ & $3(2.3)$ & $3(2.4)$ & $7(5.6)$ & $17(3.3)$ \\
\hline Insomnia & $2(1.6)$ & $1(0.8)$ & $2(1.6)$ & $3(2.4)$ & $8(1.6)$ \\
\hline Acne & $2(1.6)$ & $1(0.8)$ & $1(0.8)$ & $3(2.4)$ & 7 (1.4) \\
\hline Hirsutism & 0 & 0 & 0 & $1(0.8)$ & $1(0.2)$ \\
\hline
\end{tabular}

*Worsening of glucocorticoid-related signs or symptoms from baseline to any post-baseline visit.

MMX, Multi-Matrix System. 
rigorous endoscopy and inclusion of patients with normal baseline histology in the efficacy analyses, would very likely have contributed to the higher remission rates across all treatment groups in the mesalazine MMX studies. ${ }^{2} 11{ }^{12}$ If ORs for the benefit of treatment over placebo on remission rates are compared, however, budesonide MMX $9 \mathrm{mg}$ (OR 4.49; 95\% CI 1.47 to 13.72 ) compares favourably with mesalazine MMX $4.8 \mathrm{~g}$ (OR 2.78; 95\% CI 1.27 to 6.06$){ }^{11}$ and also with mesalazine $4 \mathrm{~g}$ (OR 2.56;95\% CI 1.05 to 6.25$)^{23}$ and adalimumab $160 / 80$ (OR $1.92 ; 95 \%$ CI 1.03 to 3.58 ). ${ }^{24}$ This highlights the importance of considering relative efficacy. The overall remission rates for placebo versus active drug in these three studies, albeit representing slightly different patient populations, were $12.9 \%$ vs $34.1 \%, 12.2 \%$ vs $26.3 \%$, and $9.4 \%$ vs $16.5 \%$, respectively.

Budesonide MMX 9 mg increased clinical improvement and endoscopic improvement rates compared with placebo, but these differences did not reach statistical significance. Nevertheless, histological healing (which appears to predict long-lasting remission) and symptom resolution (perceived improvement by patients) were statistically superior in the budesonide MMX $9 \mathrm{mg}$ group compared with the placebo group. The efficacy of budesonide MMX $9 \mathrm{mg}$ and $6 \mathrm{mg}$ versus placebo has also been studied in an almost identically designed, 8 -week phase III study (CORE I) conducted in the USA, Canada, Mexico and India that used a non-powered control arm. ${ }^{25}$ The CORE I study results were very similar to those obtained in the current study, showing that budesonide MMX 9 mg was effective at inducing remission in active, mild-to-moderate UC. The rates of combined clinical and endoscopic remission at week 8 with budesonide MMX $9 \mathrm{mg}$ and placebo were $17.9 \%$, and $7.4 \%$, respectively $(\mathrm{p}=0.0143)$. As in the present study, budesonide MMX $9 \mathrm{mg}$ was also associated with significantly higher rates of symptom resolution than placebo at week $8(28.5 \%$ vs $16.5 \%$, respectively; $\mathrm{p}=0.0258) .^{25}$ The consistent rates of remission and symptom resolution between these two studies further support the efficacy of budesonide MMX $9 \mathrm{mg}$ in patients with active, mild-to-moderate UC.

The main limitation of this study was the high number of patients recruited and subsequently excluded from the efficacy analyses due to violations in GCP or lack of active UC on histological analysis. Although lack of active UC on histological analysis should, ideally, have been a prospective exclusion criterion, histology could only be assessed practically after study initiation due to the lengthy time required for central analysis. Objective assessment of active disease was, nonetheless, considered essential, as anti-inflammatory agents cannot reasonably be expected to work in the absence of inflammation. In our study, $15.1 \%$ of patients (77/511) with apparent clinical and endoscopic evidence of active disease did not, in fact, have histological evidence of active inflammation. When patients from sites with major GCP violations were removed from the analysis, 9.2\% (47/511) of patients did not have active disease. These numbers are slightly higher than the CORE I study with budesonide MMX, which had a relatively low percentage $(3.3 \%(17 / 510))$ of patients without active disease. It is important to note that the CORE I and CORE II studies, though similar in design, were conducted in two mutually exclusive regions and using two separate central laboratories for histology. Typical clinical trials in UC have reported higher normal histology numbers than those reported above. As an example, a recent post hoc analysis of an induction-of-remission trial of mesalazine granules (Apriso) in UC showed that $13.7 \%$ of patients $(52 / 380)$ had no objective histological evidence of active inflammation at baseline despite the presence of clinically and endoscopically active disease. $^{26}$ Central reading of video endoscopies in near-real time, using a validated scoring instrument, ${ }^{27}$ may be a more practical approach to independent confirmation of disease activity for such patients. The number of GCP violations was also a concern, but they were restricted to four sites: all patients from these sites were excluded from the efficacy (but not safety) analyses. It should be noted that a substantial number of the patients who did not have evidence of active disease on histology at baseline were recruited at these sites. Reassuringly, the sensitivity analysis in which all the patients who were randomised and dosed (ie, the conventional intention-to-treat population) were analysed (with patients excluded from the mITT population set to non-responder imputation) still showed a highly significant effect of budesonide MMX $9 \mathrm{mg}$ versus placebo on combined clinical and endoscopic remission rates (15.1\% vs $3.1 \%$, respectively, $\mathrm{p}=0.0008)$.

Overall, budesonide coupled to the MMX colonic release system was well tolerated and raised no new safety concerns, with an AE profile not clinically different to placebo. Reductions in morning plasma cortisol levels occurred at a higher frequency in both budesonide MMX groups and the Entocort EC group, which is an expected consequence of any oral steroid treatment. However, mean morning plasma cortisol levels remained within the normal range at all times, and a subsequent extended maintenance treatment study with budesonide MMX $6 \mathrm{mg}$ over 12 months showed no further decline. $^{28} 29$ There were also no notable increases in glucocorticosteroid-related side effects with budesonide MMX compared with placebo. These data support the hypothesis that low bioavailability and targeted delivery of budesonide limits side effects. The CORE I and $\mathrm{II}^{25}$ studies were designed only to evaluate short-term efficacy (8 weeks) and not maintenance therapy. Since steroids have not to date been shown to prevent relapse in UC, conventional maintenance therapy after a clinical response to budesonide MMX with 5-ASA or thiopurines can be expected to be standard practice. There will be some patients who have mild but persistently active disease and for these patients budesonide MMX might reasonably be continued for longer than 8 weeks on an individual basis, but this is not supported by the current data and needs more study.

In conclusion, budesonide MMX $9 \mathrm{mg}$ daily was safe and effective for the induction of remission of active, mild-to-moderate UC. The data also highlight the value of using robust endpoints and the importance of ensuring histological evidence of active disease prior to initiating studies of antiinflammatory agents. Colonic-release budesonide may therefore be an alternative to conventional corticosteroid therapy for the treatment of active, mild-to-moderate UC.

\footnotetext{
Author affiliations

${ }^{1}$ Translational Gastroenterology Unit, John Radcliffe Hospital, Oxford, UK

${ }^{2}$ Istituto Clinico Humanitas, Milan, Italy

${ }^{3}$ Institute for Digestive Research, Lithuanian University of Health Sciences, Kaunas, Lithuania

${ }^{4}$ Regional Clinical Hospital named after N.A. Semachko, Nizhny Novogrod, Russian

Federation

${ }^{5}$ Department of Gastroenterology, Academic Medical Center, Amsterdam, The

Netherlands

${ }^{6}$ Department of Gastroenterology, Alfred Hospital and Monash University,

Melbourne, Australia

${ }^{7}$ Cosmo Technologies Ltd, Dublin, Ireland

${ }^{8}$ Santarus, San Diego, California, USA

${ }^{9}$ Ferring Pharmaceuticals, St Prex, Switzerland

${ }^{10}$ CROSS Metrics S.A., Mendrisio, Switzerland

${ }^{11}$ Division of Gastroenterology, University of California San Diego, La Jolla,

California, USA
} 
Acknowledgements We would like to acknowledge the principal investigators in this study: G Acute, O Antipova, N Arebi, O Arutyunov, Y Avni, A Bazlevych, I Beales, R Befrits, T Borody, Y Bouhnik, I Bunganic, R Cannizzaro, S Cernok, I Chopey, I Ciecko-Michalska, D Dobru, JL Dupas, A Eriksson, A Fich, A Fraticiu, A Goldis, B Golovenko, M Gregus, L Grinevitch, H Herterveig, M Horynski, M Huorka, L Jonaitis, E Kazenaite, A Keegan, A Khrustalev, G Kiudelis, A Kratky, L Kuzela, M Lemann, A Lenghel, LV Lenskaya, R Leong, J Lind, R Lofberg, L Lukac, F Luzza, A Maelt, B Margus, S Minushkin, Y Niv, C Nwokolo, A Oseshnyuk, P Oset, MF Osipenko, M Parkes, S Peralta, R Petryka, E Pirogova, C Prantera, J Romatowski, R Salupere, J Satsangi, V Savarino, A Shvarts, V Simanenkov, H Soloviev, B Starostin, Y Stepanov, GC Sturniolo, Z Telyatnikova, M Tkachenko, A Tkachev, I Tolmanis, N Tryschuk, R Vanagaitiene, R Vasyl, M Vecchi, R Voiosu, Y Volkov, EP Yakovenko, I Yurkov, M Zoli. Medical writing assistance was provided by Andrew Brittain of GeoMed.

Contributors ST, SD, LK, OA, GD, PRG, LM, RJ, EDB, JM, and WJS were involved in the study design and/or collection of data. MR provided the statistical analysis for the manuscript. All authors contributed to writing and reviewing of all drafts of the manuscript. All authors approved the version of the manuscript for submission.

Funding Cosmo Pharmaceuticals provided funding for this study. Medical writing assistance was funded by Ferring Pharmaceuticals, St Prex, Switzerland.

Competing interests SPLT has received consulting fees from Abbott, Asahi-Kasei, Bristol-Myers Squibb, Cosmo Technologies, Coronado Biosciences, Ferring Pharmaceuticals, Genentech, Genzyme Corp, GlaxoSmithKline, Janssen, Lexicon Pharmaceuticals, Merck Research Laboratories, Millennium Pharmaceuticals, Nisshin Kyorin Pharmaceuticals, Novartis, Novo Nordisk, NPS Pharmaceuticals, PDL Biopharma, Pfizer, Procter and Gamble, Santarus, Schering Plough, Shire Pharmaceuticals, Sigmoid Pharma Ltd, Tillotts Pharma AG, TxCell SA, UCB Pharma, and Warner Chilcott UK Ltd; research grants from Abbott, Genentech, GlaxoSmithKline, Janssen, Novartis, Pfizer, Procter and Gamble, Shire Pharmaceuticals and UCB Pharma; payments for lectures/speakers bureaux from Abbott, Janssen, Ferring Pharmaceuticals and Warner Chilcott; and holds no stock/ stock options. SD has served as a speaker, a consultant and an advisory board member for Schering-Plough, Abbott Laboratories, Merck \& Co, UCB Pharma, Ferring, Cellerix, Millenium Takeda, Nycomed, Pharmacosmos, Actelion, Alphawasserman, Genentech, Pfizer, Astra Zeneca, Novo Nordisk, Cosmo Pharmaceuticals, Vifor, and Johnson and Johnson. GD has received consulting fees from Abbott, ActoGeniX NV, Atlantic Healthcare Ltd, Boehringer-Ingelheim, Bristol-Myers Squibb, ChemoCentryx, CoMentis, Cosmo Technologies, EnGene Inc, Ferring Pharmaceuticals, Given Imaging, GlaxoSmithKline, Merck Research Laboratories, Millennium Pharmaceuticals, Norgine, Novo Nordisk, PDL Biopharma, Pfizer, Schering Plough, Shire Pharmaceuticals, Sigmoid Pharma Ltd, Takeda, Teva Pharmaceuticals, Tilliotts Pharma AG, UCB Pharma; research grants from Abbott, GlaxoSmithKline, Dr Falk Pharma, Janssen Biologics, and MSD; payments for lectures/speakers bureaux from Abbott, Ferring, Janssen, MSD, Norgine and UCB; and has stock/stock options in EnGene Inc. PRG has received consulting fees from Ferring Pharmaceuticals, Abbott, Janssen, Schering-Plough and Merck; research support from Falk Pharma GmbH, Shire, Orphan Australia, Fresenius Kabi and Norgine; and payment for lectures from Abbott, Merck and Janssen. LM and RJ are employees of Cosmo Technologies Ltd, Dublin Ireland. EDB is an employee of Santarus, San Diego, California, USA. JM is an employee of Ferring Pharmaceuticals, St Prex, Switzerland. MR is an employee of CROSS Metrics S.A., Mendrisio, Switzerland. WJS has received consulting fees from Abbott, ActoGeniX NV, AGI Therapeutics Inc, Alba Therapeutics Corp, Albireo, Alfa Wasserman, Amgen, AM-Pharma BV, Anaphore, Astellas, Athersys Inc, Atlantic Healthcare Ltd, Aptalis, BioBalance Corp, Boehringer-Ingelheim, Bristol-Myers Squibb, Celgene, Celek Pharmaceuticals, Cellerix SL, Cerimon Pharmaceuticals, ChemoCentryx, CoMentis, Cosmo Technologies, Coronado Biosciences, Cytokine Pharmasciences, Eagle Pharmaceuticals, EnGene Inc, Eli Lilly, Enteromedics, Exagen Diagnostics Inc, Ferring Pharmaceuticals, Flexio Therapeutics Inc, Funxional Therapeutics Ltd, Genzyme Corp, Gilead Sciences, Given Imaging, GlaxoSmithKline, Human Genome Sciences, Ironwood Pharmaceuticals, KaloBios Pharmaceuticals, Lexicon Pharmaceuticals, Lycera Corp, Meda Pharmaceuticals, Merck Research Laboratories, Merck Serono, Millennium Pharmaceuticals, Nisshin Kyorin Pharmaceuticals, Novo Nordisk, NPS Pharmaceuticals, Optimer Pharmaceuticals, Orexigen Therapeutics Inc, PDL Biopharma, Pfizer, Procter and Gamble, Prometheus Laboratories, ProtAb Ltd, Purgenesis Technologies Inc, Relypsa Inc, Roche, Salient Pharmaceuticals, Salix Pharmaceuticals, Santarus, Schering Plough, Shire Pharmaceuticals, Sigmoid Pharma Ltd, Sirtris Pharmaceuticals, SLA Pharma UK Ltd, Targacept, Teva Pharmaceuticals, Therakos, Tilliotts Pharma AG, TxCell SA, UCB Pharma, Viamet Pharmaceuticals, Vascular Biogenics Ltd, Warner Chilcott UK Ltd and Wyeth; research grants from Abbott, Bristol-Myers Squibb, Genentech, GlaxoSmithKline, Janssen, Millennium Pharmaceuticals, Novartis, Pfizer, Procter and Gamble, Shire Pharmaceuticals and UCB Pharma; payments for lectures/speakers bureaux from Abbott, Bristol-Myers Squibb and Janssen; and holds stock/stock options in Enteromedics. LK and OA declare no competing interests.

Ethics approval Independent Ethics Committees.
Provenance and peer review Not commissioned; externally peer reviewed.

Open Access This is an Open Access article distributed in accordance with the Creative Commons Attribution Non Commercial (CC BY-NC 3.0) license, which permits others to distribute, remix, adapt, build upon this work non-commercially, and license their derivative works on different terms, provided the original work is properly cited and the use is non-commercial. See: http://creativecommons.org/ licenses/by-nc/3.0/

\section{REFERENCES}

1 Danese S, Fiocchi C. Ulcerative colitis. N Engl J Med 2011;365:1713-25.

2 Sandborn WJ, Kamm MA, Lichtenstein GR, et al. MMX Multi Matrix System mesalazine for the induction of remission in patients with mild-to-moderate ulcerative colitis: a combined analysis of two randomized, double-blind, placebo-controlled trials. Aliment Pharmacol Ther 2007;26:205-15.

3 Dignass A, Lindsay JO, Sturm A, et al. Second European-evidence-based consensus on the management of ulcerative colitis. J Crohns Colitis 2012;6:991-1030.

4 Ford AC, Bernstein CN, Khan KJ, et al. Glucocorticosteroid therapy in inflammatory bowel disease: systematic review and meta-analysis. Am J Gastroentrol 2011;106:590-9.

5 Hvizdos KM, Jarvis B. Budesonide inhalation suspension: a review of its use in infants, children and adults with inflammatory respiratory disorders. Drugs 2000;60:1141-78.

6 Sherlock ME, Seow CH, Steinhart AH, et al. Oral budesonide for induction for remission in ulcerative colitis. Cochrane Database Syst Rev 2010:CD007698.

7 Seow CH, Benchimol El, Griffiths AM, et al. Budesonide for induction of remission in Crohn's disease. Cochrane Database Syst Rev 2008:CD000296.

8 Kozuch PL, Hanauer SB. Treatment of inflammatory bowel disease: a review of medical therapy. World J Gastroenterol 2008;14:354-77.

9 Gross V, Bunganic I, Belousova EA, et al. $3 \mathrm{~g}$ mesalazine granules are superior to $9 \mathrm{mg}$ budesonide for achieving remission in active ulcerative colitis: a double-blind, double-dummy, randomised trial. J Crohns Colitis 2011;5:129-38.

10 Brunner M, Ziegler S, Di Stefano AF, et al. Gastrointestinal transit, release and plasma pharmacokinetics of a new oral budesonide formulation. $\mathrm{Br} J \mathrm{Clin}$ Pharmacol 2006:61:31-8.

11 Lichtenstein GR, Kamm MA, Boddu P, et al. Effect of once- or twice-daily MMX mesalamine (SPD476) for the induction of remission of mild to moderately active ulcerative colitis. Clin Gastroenterol Hepatol 2007;5:95-102.

12 Kamm MA, Sandborn WJ, Gassull M, et al. Once-daily, high-concentration MMX mesalamine in active ulcerative colitis. Gastroenterology 2007;132:66-75.

13 Kamm MA, Lichtenstein GR, Sandborn WJ, et al. Randomised trial of once- or twice-daily MMX mesalazine for maintenance of remission in ulcerative colitis. Gut 2008; 57:893-902.

14 D'Haens GR, Kovacs A, Vergauwe $P$, et al. Clinical trial: Preliminary efficacy and safety study of a new Budesonide MMX® $9 \mathrm{mg}$ extended-release tablets in patients with active left-sided ulcerative colitis. J Crohns Colitis 2010;4:153-60.

15 Sutherland LR, Martin F, Greer S, et al. 5-Aminosalicylic acid enema in the treatment of distal ulcerative colitis, proctosigmoiditis, and proctitis. Gastroenterology 1987;92:1894-8.

16 D'Haens G, Sandborn WJ, Feagan BG, et al. A review of activity indices and efficacy end points for clinical trials of medical therapy in adults with ulcerative colitis Gastroenterology 2007;132:763-86.

17 Rachmilewitz D. Coated mesalazine (5-aminosalicylic acid) versus sulphasalazine in the treatment of active ulcerative colitis: a randomised trial. BMJ 1989;298:82-6.

18 Saverymuttu $\mathrm{SH}$, Camilleri $\mathrm{M}$, Rees $\mathrm{H}$, et al. Indium 111-granulocyte scanning in the assessment of disease extent and disease activity in inflammatory bowel disease. A comparison with colonoscopy, histology, and fecal indium 111-granulocyte excretion. Gastroenterology 1986;90:1121-8.

19 Kraemer HC, Morgan GA, Leech NL, et al. Measures of clinical significance. J Am Acad Child Adolesc Psychiatry 2003;42:1524-9.

20 Schulz KF, Altman DG, Moher D, for the CONSORT Group. CONSORT 2010 statement: updated guidelines for reporting parallel group randomised trials. BMJ 2010:340:c332.

21 Travis $S P$, Higgins $P D$, Orchard $T$, et al. Review article: defining remission in ulcerative colitis. Aliment Pharmacol Ther 2011;34:113-24.

22 Colombel JF, Rutgeerts $\mathrm{P}$, Reinisch $\mathrm{W}$, et al. Early mucosal healing with infliximab is associated with improved long-term clinical outcomes in ulcerative colitis. Gastroenterology 2011:141:1194-201.

23 Roberts Laboratories Inc. Pentasa ${ }^{\circledR}$ prescribing information. Eatontown, New Jersey: Roberts Pharmaceutical Corp., 1999.

24 Reinisch W, Sandborn WJ, Hommes DW, et al. Adalimumab for induction of clinical remission in moderately to severely active ulcerative colitis: results of a randomised controlled trial. Gut 2011:60:780-7.

25 Sandborn W, Travis S, Moro L, et al. Once-daily budesonide MMX® extended-release tablets induce remission in patients with mild to moderate ulcerative colitis: results from the CORE I study. Gastroenterology 2012:143:1218-26. 
26 Wolff $\mathrm{S}$, Terheggen $\mathrm{G}$, Mueller $\mathrm{R}$, et al. Are endoscopic assessments a reliable measure for trials in ulcerative colitis? Gastroenterology 2011;140(Suppl 1):S389.

27 Travis SP, Schnell D, Krzeski P, et al. Developing an instrument to assess the endoscopic severity of ulcerative colitis: the Ulcerative Colitis Endoscopic Index of Severity (UCEIS). Gut 2012;61:535-42.

28 Lichtenstein GR, Danese S, Ballard ED, et al. Effect of budesonide MMX $6 \mathrm{mg}$ on the hypothalamic-pituitary-adrenal (HPA) axis in patients with ulcerative colitis: results from a phase III, 12 month safety and extended use study. Gastroenterology 2012;142(Suppl 1):S785.

29 Travis S, Danese S, Ballard ED, et al. Safety analysis of budesonide MMX $6 \mathrm{mg}$ used for the maintenance of remission in patients with ulcerative colitis: results from a phase III, 12 month safety and extended use study. Gastroenterology 2012;142 (Suppl 1):S566-7. 